\title{
Prevalence of Cardiac Depression and its Related Factors among Patients with Acute Coronary Syndrome
}

\author{
Amir Hossein Goudarzian', Hamid Sharif $\mathrm{Nia}^{2}$, Heydar Tavakoli ${ }^{3}$, Mohammad Ali Soleimani ${ }^{4}$, \\ Ameneh Yaghoobzadeh ${ }^{5}$, Fariba Tabari ${ }^{*}{ }^{*}$ and Mozhgan Taebei ${ }^{7}$ \\ 'Student Research Committee, Mazandaran University of Medical Sciences, Sari, Iran \\ ${ }^{2}$ School of Nursing and Midwifery Amol, Mazandaran University of Medical Sciences, Sari, Iran \\ 3Imam Reza Hospital Amol, Mazandaran University of Medical Sciences, Sari, Iran \\ ${ }^{4}$ Social Determinants of Health Research Center, Qazvin University of Medical Sciences, Qazvin, Iran \\ ${ }^{5}$ Tehran University of Medical Sciences, Tehran, Iran \\ ${ }^{6}$ School of Nursing and Midwifery, Tehran University of Medical Sciences, Tehran, Iran; ftabari@tums.ac.ir \\ ${ }^{7}$ School of Nursing and Midwifery Razi, Kerman University of Medical Sciences, Kerman, Iran
}

\begin{abstract}
Cardiac depression is one of the most common psychological reactions of patients with acute coronary syndrome (ACS). This study aimed to determine the prevalence of cardiac depression and its related factors among patients with ACS. This cross-sectional study was conducted during 2016 in patients with ACS who were admitted to hospitals affiliated to the Mazandaran University of Medical Sciences, Iran. In the present study, 407 patients completed the Cardiac Depression Scale (CDS) within two months (March - June). The data were analyzed by a chi-square test and a general linear model multivariate analysis. According to the results, the mean cardiac depression score in patients with ACS was $109.00 \pm 16.49$ (CI95: 107.39 to 110.60). Among the participants, 37 (9.1\%), 72 (17.7\%), and 298 (73.2\%) patients had mild, moderate, and severe levels of depression, respectively. Although the two-way ANOVA was not significant, but there was a difference between cardiac depression score of a type of ACS. Given the high prevalence of cardiac depression among these patients, it is necessary to develop measures for routine screening in cardiac treatment units.
\end{abstract}

Keywords: Acute Coronary Syndrome, Depression, Sleep Quality

\section{Introduction}

At the beginning of the twentieth century, cardiovascular diseases (CVDs) constituted less than $10 \%$ of deaths in the world. However, with the passing of time and the advent of the industrial revolution and its effects on the social and economic aspects of communities, the incidence of this disease increase ${ }^{1}$. Acute myocardial infarction (AMI) is the most common cardiovascular disease. It has the second rank among diseases in developed and developing countries $^{2}$. Approximately 1.1 million cases of AMI occur each year in the United States and $44.81 \%$ deaths are due to $\mathrm{AMI}^{3}$. In Iran, CVDs are the leading cause of death and AMI is the cause of half of the mortality rate attributed to
$\mathrm{CVDs}^{4}$. Every year, about 3.6 million people are admitted to hospitals of the Ministry of Health and Medical Education due to CVDs, and CVDs account for about $46 \%$ of deaths thus far ${ }^{5}$. Acute coronary syndrome (ACS), in addition to physical consequences, has many psychological consequences ${ }^{6}$. Depression, delirium, cognitive disorders, fear, anxiety, and stress are among the psychological reactions of ACS patients, and depression is one of the most common psychological consequences among these patients ${ }^{7,8}$. The physiological mechanisms accounting for this association are unclear. Hypothalamic-pituitaryadrenal dysregulation, diminished heart rate variability, altered blood platelet function and noncompliance with medical treatments have been proposed as mechanisms

*Author for correspondence 
underlying depression and cardiovascular disease. Recent evidence also suggests that reduced baroreflex sensitivity, impaired immune function, chronic fatigue and the co-morbidity of depression and anxiety may be involved in the relationship between depression and cardiovascular dysregulation'. Depression reduces the patients' desire to follow the recommendations for the reduction of CVD risk factors ${ }^{10}$. This has a negative impact on the course of the disease as well as the physical and psychological recovery process of the patients ${ }^{6,11,12}$. According to previous studies, the rate of depression in patients after AMI is three times higher than the general population ${ }^{13,14}$. The results of the study by Hosseini et al. showed that the prevalence of depression in the first 48 hours after AMI was $60.7 \%{ }^{15}$. AMI is a life-threatening disease: thus, it can be expected to have a stressful role in the development of depression. AMI, due to limiting the physical activity of the individual, also causes depression as its secondary effect. In the past 40 years, more than 60 prospective studies have examined the relationship between depression and CVDs. Based on the findings of these studies, the incidence of depression among patients with CVD was three times higher than that in the general population ${ }^{16,17}$. Bayani et $a l^{18}$ reported the prevalence of depression using the Hamilton Depression Scale in 238 patients with CVDs as $41.2 \%$. Carney et al. ${ }^{19}$ reported the prevalence of depression among 70 patients with coronary syndrome using the DIS questionnaire as $23 \%$. Due to the direct or indirect effect of depression on the prognosis of heart disease, screening, and treatment of depression in these patients seems necessary. According to a review study, the majority of cardiac patients use tricyclic antidepressants (TCAs), one of TCAs and bupropion and selective serotonin reuptake inhibitors (SSRIs) to the treatment of depression ${ }^{20}$. Studies on the prevalence of depression among patients with CVDs in Iran are very scattered and the Cardiac Depression Scale (CDS) was not used to obtain more accurate and correct data on the symptoms and intensity of cardiac depression in patients with ACS. Therefore, this study aimed to determine the prevalence of cardiac depression and its related factors in patients with ACS.

\section{Material and Methods}

This cross-sectional study was conducted in 2016 (March - June) on 407 patients with ACS who were admitted to the CCU of Imam Reza and Fatimeh Zahra

Vol 8(S1) | 2016 | www.informaticsjournals.com/index.php/ajprhc
Hospitals in Sari, Iran. The participants were selected via simple random sampling method. The adequacy of the sample size was determined based on the two-sided significance level of $(\alpha=0.05)$ and $80 \%$ power $(d=0.3)$. The diagnosis and admission criteria were determined by the cardiologist in relation to electrocardiographic (ECG) changes in ST segment, ST elevation MI (STEMI). STEMI is characterized as ST elevation of more than $0.2 \mathrm{mV}$ in leads V1-V4 or over $0.1 \mathrm{mV}$ in leads I, II, III, aVL, aVF, V5, and V6. Non-ST-elevation myocardial infarction (NSTEMI) is characterized as the existence of angina for more than 20 minutes along with an increase in a cardiac biochemical marker of myocardial necrosis (troponin or creatine kinase-MB), $\geqq 10 \mathrm{~mm}$ but $<20 \mathrm{~mm}$ in V1-V4, and ECG changes in ST segment depression $\geqq 10 \mathrm{~mm}$ depression at $80 \mathrm{~ms}$ following the J point and inverted T, and pathological Q waves [duration_0.03 s amplitude Q: $\mathrm{R}$ ratio $25 \%]^{21}$. Patients with mental, emotional, and verbal problems and reduced consciousness were excluded from the study.

\subsection{Instruments}

The demographic data (age, gender, economic, and educational level) and medical record form (blood pressure and blood lipid, history of alcohol and drug use, history of depression, level of activity, type of ACS, stroke location, and history of previous illness) was completed by the participants.

The Cardiac Depression Scale (CDS) by Hare et al. ${ }^{22}$ was designed specifically to assess depression in patients with CVDs. The CDS includes 26 items that measure variables such as activity, focus, rest, mind, emotions, and the difficulties of life. This tool was scored based on a Likert scale ranging from strongly disagree ${ }^{1}$ to strongly agree ${ }^{7}$. Total scores are calculated as the sum of the scores of each item and range from 26 to 182 . Higher scores indicated more severe depression ${ }^{23}$. The validity of the CDS was assessed and confirmed through content validity. The reliability of the instrument was confirmed by a study on heart diseases in Australia with Cronbach's alpha of 0.90; moreover, a 0.73 relationship with the Beck Depression Inventory (BDI) was reported in this population ${ }^{24}$. In this study, the internal consistency of the questionnaire was calculated using Cronbach's alpha coefficient $(\alpha=0.73)$.

\subsection{Data Analysis}

Statistical analysis was performed using SPSS22 (SPSS Inc., Chicago, IL, USA). The Kolmogorov-Smirnov test 
was used to assess the normal distribution of quantitative data. Descriptive and inferential statistics (chi-square, general linear model: univariate analysis of variance) were used for data analysis. The statistical significance level of all tests was considered as less than 0.05 .

\subsection{Ethical Consideration}

The present study was approved by the ethics committee of the associated university in 2015. Patients were informed of the study aims and procedures, and that participation was voluntary and would not affect medical care before signing an informed consent form. Patient confidentiality was ensured by completing all study procedures in a quiet treatment area. To ensure that a broad cross-section of patients was allowed to participate in the study, a trained research assistant who was part of the study team provided support when needed. All personal data were de-identified by assigning codes to the participants.

\section{Results}

According to the results of this study, the mean \pm SD of the age of patients with ACS in the study was $63.72 \pm$ 16.37 years (95\% CI: 65.32 to 62.12 ). The mean cardiac depression scores in patients with ACS was $109.00 \pm 16.49$ (95\% CI: 107.39 to 110.60$)$, and 37 (9.1\%), 72 (17.7\%), and $298(73.2 \%)$ of the patients had mild, moderate, and severe depression levels, respectively. Table 1 shows the association of demographic variables with the type of ACS.

According to chi-square test (Table 1), gender ( $p$ $=0.03)$ and smoking status $(p=0.006)$ had statistically

Table 1. Association of demographic characters with type of ACS

\begin{tabular}{|c|c|c|c|c|c|c|}
\hline \multicolumn{3}{|l|}{ Variable } & UA $(n=129)$ & STEMI $(n=213)$ & NSTEMI $(n=65)$ & p-Value \\
\hline \multirow[t]{2}{*}{ Sex } & \multicolumn{2}{|c|}{ Male $(n=224)$} & $65(29 \%)$ & $114(50.9 \%)$ & $45(20.1 \%)$ & \multirow[t]{2}{*}{0.03} \\
\hline & \multicolumn{2}{|c|}{ Female $(n=183)$} & $64(35 \%)$ & $99(54.1 \%)$ & $20(10.9 \%)$ & \\
\hline \multirow[t]{4}{*}{ Economic Status } & \multicolumn{2}{|c|}{ Weak $(n=126)$} & $47(37.3 \%)$ & $61(48.4 \%)$ & $18(14.3 \%)$ & \multirow[t]{4}{*}{0.06} \\
\hline & \multicolumn{2}{|c|}{ Intermediate $(n=168)$} & $54(32.1 \%)$ & $80(47.6 \%)$ & $34(20.2 \%)$ & \\
\hline & \multicolumn{2}{|c|}{ Good $(n=106)$} & $25(23.6 \%)$ & $68(64.2 \%)$ & $13(12.3 \%)$ & \\
\hline & \multicolumn{2}{|c|}{ Well $(n=7)$} & $3(42.9 \%)$ & $4(57.1 \%)$ & 0 & \\
\hline \multirow[t]{3}{*}{ Education status } & \multicolumn{2}{|c|}{ Illiterate $(\mathrm{n}=221)$} & $72(32.6 \%)$ & $112(50.7 \%)$ & $37(16.7 \%)$ & \multirow[t]{3}{*}{0.80} \\
\hline & \multicolumn{2}{|c|}{ Diploma-BS $(\mathrm{n}=178)$} & $54(30.3 \%)$ & $98(55.1 \%)$ & $26(14.6 \%)$ & \\
\hline & \multicolumn{2}{|c|}{ MCs and upper $(\mathrm{n}=8)$} & $3(37.5 \%)$ & $3(37.5 \%)$ & $2(25.0 \%)$ & \\
\hline \multirow[t]{2}{*}{ Hyperlipidemia } & \multicolumn{2}{|c|}{ Yes $(n=220)$} & $68(30.9 \%)$ & $122(55.5 \%)$ & $30(13.6 \%)$ & \multirow[t]{2}{*}{0.27} \\
\hline & \multicolumn{2}{|c|}{ No $(n=187)$} & $61(32.6 \%)$ & $91(48.7 \%)$ & $35(18.7 \%)$ & \\
\hline \multirow[t]{2}{*}{ Smoking } & \multicolumn{2}{|c|}{ Yes $(n=166)$} & $47(28.3 \%)$ & $81(48.8 \%)$ & $38(22.9 \%)$ & \multirow[t]{2}{*}{0.006} \\
\hline & \multicolumn{2}{|c|}{ No $(n=241)$} & $82(34.0 \%)$ & $132(54.8 \%)$ & $27(11.2 \%)$ & \\
\hline \multirow[t]{2}{*}{ History of alcohol use } & \multicolumn{2}{|c|}{ Yes $(n=77)$} & $28(36.4 \%)$ & $35(45.5 \%)$ & $14(18.2 \%)$ & \multirow[t]{2}{*}{0.406} \\
\hline & \multicolumn{2}{|l|}{ No (330) } & $101(30.6 \%)$ & $178(53.9 \%)$ & $51(15.5 \%)$ & \\
\hline \multirow{2}{*}{$\begin{array}{l}\text { History of heart disease in } \\
\text { family }\end{array}$} & \multicolumn{2}{|c|}{ Yes $(n=297)$} & $98(33 \%)$ & $151(50.8 \%)$ & $48(16.2 \%)$ & \multirow[t]{2}{*}{0.583} \\
\hline & \multicolumn{2}{|c|}{ No $(n=110)$} & $31(28.2 \%)$ & $62(56.4 \%)$ & $17(15.5 \%)$ & \\
\hline \multirow[t]{2}{*}{ Family depression history } & Yes $(n=13$ & & $42(32.1 \%)$ & $72(55 \%)$ & $17(13 \%)$ & 0.51 \\
\hline & No $(n=27$ & & $87(31.5 \%)$ & $141(51.1 \%)$ & $48(17.4 \%)$ & \\
\hline Candidate of CABG & Yes $(n=12$ & & $37(29.1 \%)$ & $65(51.2 \%)$ & $25(19.7 \%)$ & 0.364 \\
\hline & No $(n=28$ & & $92(32.9 \%)$ & $148(52.9 \%)$ & $40(14.3 \%)$ & \\
\hline Past medical history & $\mathrm{CHF}$ & Yes $(n=74)$ & $19(25.7 \%)$ & $42(56.8 \%)$ & $13(17.6 \%)$ & 0.468 \\
\hline & & No $(n=333)$ & $110(33 \%)$ & $171(51.4 \%)$ & $52(15.6 \%)$ & \\
\hline & Diabetes & Yes $(n=144)$ & $48(33.3 \%)$ & $78(54.2 \%)$ & $18(12.5 \%)$ & 0.366 \\
\hline & & No $(n=263)$ & $81(30.8 \%)$ & $135(51.3 \%)$ & $47(17.9 \%)$ & \\
\hline
\end{tabular}


Table 2. Differences among type of ACS based on cardiac depression scores

\begin{tabular}{lcccc}
\hline Type of ACS & Mean (SD) & 95\% CI & F & p \\
\hline Unstable Angina (UA) & $106.4031(18.363)$ & 103.20 to 109.60 & & \\
ST segmentation elevation MI (STEMI) & $110.9155(14.673)$ & 108.93 to 112.89 & \multirow{2}{*}{1.04} & 0.694 \\
ST segmentation elevation MI (STEMI) & $107.8923(17.629)$ & 103.52 to 112.26 & & \\
Total & $\mathbf{1 0 9 . 0 0 2 5 ( 1 6 . 4 9 2 )}$ & $\mathbf{1 0 7 . 3 9}$ to 110.60 & & \\
\hline
\end{tabular}

significant differences among ACS types. Multifactorial ANOVA test results (Table 2) showed that the mean cardiac depression score in patients with CVD with UA (106.40 \pm 18.36$)$, STEMI $(110.91 \pm 14.67)$, and NSTEMI $(107.86 \pm 17.62)$ did not have a significant difference [eta $=0.002, p=0.694, \mathrm{~F}(401,1)=1.04]$.

\section{Discussion}

Previous researchers suggested that depression may be a risk factor for coronary heart disorders $(\mathrm{CHD})^{25}$. The more accurate evaluation showed that depression affects the automatic adjustment of the heart, sub-chronic inflammation, cardiovascular endothelial function, platelet function, and omega fatty acids levels ${ }^{26}$. Therefore, like diabetes, reduced physical activity, or weight gain, depression is among the risk factors for CVD and is perhaps even more important than some of them ${ }^{27}$. Of the 407 patients under study, 37 (9.1\%), 72 (17.7\%), and $298(73.2 \%)$ of the patients had mild, moderate, and severe depression levels, respectively. These results were consistent with the findings of similar studies ${ }^{24,28,29}$. Moraska et al. ${ }^{30}$ studied patients with CVDs admitted to the emergency unit using the Patient Health Questionnaire-9 (PHQ-9) and reported that 15\% of patients had major depression and 26\% had mild depression. Moreover, Blumenthal et al. ${ }^{31}$ assessed patients undergoing coronary artery bypass grafting (CABG) using the Center for Epidemiologic Studies-Depression (CES-D) Scale. They reported that $26 \%$ of patients had minor depression and $12 \%$ had severe depression which was not consistent with the present study results ${ }^{31}$. A possible cause of this inconsistency can be the type of instrument used to measure depression which was not designed specifically for cardiac patients. The existence of one or more than one indicator has a significant influence on the severity of depression. Consideration of this matter can, on the one hand, influence the process of assessment and the use of specific high sensitivity tools for the assessment of depression severity in patients with CVD, and on the other hand, through the consideration of its effect, impact the treatment process. Depression is the most important obstacles to treatment of heart diseases because it leads to patients' lack of acceptance of the disease and decreased motivation to continue the treatment, and it also has a negative impact on the prognosis of $\mathrm{CVD}^{32}$. The impact mechanisms of behavior in this disorder is that these patients, due to depression, have reduced physical activity, reduced self-care, increased alcohol and tobacco use, are less likely to seek medical services, and leave rehabilitation programs incomplete ${ }^{33}$. Therefore, early detection and management of this common disease are very valuable and important in the treatment of patients. In this study, gender ( $p=0.03)$, and smoking ( $p=0.006)$ had statistically significant differences among of ACS types regarding the frequency of depression. This result was consistent with that of the studies by Bayani et al. ${ }^{18}$ and Safai et al. ${ }^{34}$ which were conducted on patients with heart disease and CHD. In another study conducted on 108 patients with CVDs hospitalized in Rasht, Iran, using the CDS, no statistically significant relationship was found between gender and severity of depression ${ }^{35}$. This finding was inconsistent with the present study. This difference may be due to the differences in sample size and the evaluation of all CVDs in this study. Nevertheless, in the present study, only a specific and common category of CVDs was taken into account. In general, most studies were conducted with common psychiatry tools for evaluation of depression. Given that the instrument used in this study (CDS) was much more accurate and specific to these patients, it is suggested that future studies be conducted using this tool on a wider scale, on other types of CVDs, and with a longer duration of follow-up (even after discharge).

\section{Study Limitations}

During the period of the study, only patients in the mentioned centers were monitored and the outpatients who referred for examinations were not included in the study. Also, all of the patients with the previous history 
of disease and family history are included to study that may have an effect on the level of depression. Given that the hospitalization factor and its related measures may affect depression, the severity of depression obtained in this study cannot be extended to all patients with CVDs. Thus, it is suggested that this factor is considered in future studies.

\section{Conclusion}

Given the high prevalence of depression among patients with CVDs, it is necessary to develop routine screening measures in cardiac treatment units, so that with the early diagnosis and treatment of this disorder, faster recovery and quality of life improvement can be achieved among these patients. Therefore, cardiologists' and nurses' role in this regard is crucial.

\section{Acknowledgments}

Our special thanks go to all patients and nurses who assisted us in this research.

\section{Conflict of Interest}

There was no conflict of interest.

\section{References}

1. Estruch R, Ros E, Salas-Salvadó J, Covas MI, Corella D, Arós F, Gómez-Gracia E, Ruiz-Gutiérrez V, Fiol M, Lapetra J, Lamuela-Raventos RM. Primary prevention of cardiovascular disease with a Mediterranean diet. New England Journal of Medicine. 2013; 368(14):1279-90.

2. Basampour SS. The effect of education on anxiety before and after open heart surgery. 2004.

3. Greenlund KJ, Keenan NL, Giles WH, Zheng ZJ, Neff LJ, Croft JB, Mensah GA. Public recognition of major signs and symptoms of heart attack: seventeen states and the US Virgin Islands, 2001. American Heart Journal. 2004; 147(6):1010-6.

4. Naghavi M, Jafari N. Mortality in the 29 provinces of Iran in 2004. Tehran: Vice-Chancellor for Health, Ministry of Health and Medical Education. 2007.

5. Taghipour B, Nia HS, Soleimani MA, Afshar MH, Far SS. Comparison of the clinical symptoms of myocardial infarction in the middle-aged and elderly. Journal of Kermanshah University of Medical Sciences. 2014; 18(5):40-45.

6. Abedini A, Akbari H. Comparison of different methods of education on reducing the anxiety of patients with myocardial infarction. Iran Journal of Nursing. 2012; 24(74):36-44.

7. Dunderdale K, Thompson DR, Miles JN, Beer SF, Furze G. Quality-of-life measurement in chronic heart failure: do we take account of the patient perspective? European Journal of Heart Failure. 2005; 7(4):572-82.

8. Fried EI, Nesse RM. Depression sum-scores don't add up: why analyzing specific depression symptoms is essential. BMC Medicine. 2015; 13(1):1-2.

9. Grippo AJ, Johnson AK. Biological mechanisms in the relationship between depression and heart disease. Neuroscience and Biobehavioral Reviews. 2002; 26(8):941-62.

10. Meneses R. Depression in patients with myocardial infarction. Revista portuguesa de cardiologia: orgao oficial da Sociedade Portuguesa de Cardiologia=Portuguese Journal of Cardiology: an official Journal of the Portuguese Society of Cardiology. 2007; 26(11):1143-65.

11. Jr CV. Association between depression and development of coronary artery disease: pathophysiologic and diagnostic implications. Vascular Health and Risk Management. 2011; 7(1):159-64.

12. Schrader G, Cheok F, Hordacre AL, Guiver N. Predictors of depression three months after cardiac hospitalization. Psychosomatic Medicine. 2004; 66(4):514-20.

13. Lichtman JH, Bigger JT, Blumenthal JA, Frasure-Smith N, Kaufmann PG, Lespérance F, Mark DB, Sheps DS, Taylor $\mathrm{CB}$, Froelicher ES. Depression and coronary heart disease recommendations for screening, referral, and treatment: a science advisory from the American Heart Association Prevention Committee of the Council on Cardiovascular Nursing, Council on Clinical Cardiology, Council on Epidemiology and Prevention, and Interdisciplinary Council on Quality of Care and Outcomes Research: endorsed by the American Psychiatric Association. Circulation. 2008; 118(17):1768-75.

14. Williams RB. Depression after heart attack: why should I be concerned about depression after a heart attack? Circulation. 2011; 123(25):639-40.

15. Hosseini H, Tabiban S, Samarbakhsh A. Depression following the first attack of myocardial infarction. Bimonthly Research Journal Pejouhandeh. 2006; 5(10):317-20.

16. Carney RM, Blumenthal JA, Stein PK, Watkins L, Catellier D, Berkman LF, Czajkowski SM, O'Connor C, Stone PH, Freedland KE. Depression, heart rate variability, and acute myocardial infarction. Circulation. 2001; 104(17):2024-8.

17. Wulsin LR, Singal BM. Do depressive symptoms increase the risk for the onset of coronary disease? A systematic quantitative review. Psychosomatic Medicine. 2003; 65(2):201-10.

18. Bayani B, Yousefi S, Bayani M, Shirmohammadi M, Alimoradi A, Falsoleiman H, Yazdi N, Arbabi M. Depression and anxiety in a cardiovascular outpatient clinic: a descriptive study. Iranian Journal of Psychiatry. 2011; 6(3):125.

19. Carney RM, Freedland KE, Jaffe AS. Insomnia and depression prior to myocardial infarction. Psychosom Med. 1990; 52(6):603-19. 
20. Mavrides N, Nemeroff C. Treatment of depression in cardiovascular disease. Depression and Anxiety. 2013; 30(4):328-41.

21. Sharif Nia H, Haghdoost AA, Nazari R, Bahrami N, Soleimani MA, Pormand K. Relationship of risk factors and ST segment changes with symptoms of acute coronary syndrome. Koomesh. 2013 Sep 15; 15(1):46-53.

22. Hare DL, Davis CR. Cardiac depression scale: validation of a new depression scale for cardiac patients. Journal of Psychosomatic Research. 1996; 40(4):379-86.

23. Wang W, Thompson DR, Chair SY, Hare DL. A psychometric evaluation of a Chinese version of the Cardiac Depression Scale. Journal of Psychosomatic Research. 2008; 65(2):123-9.

24. Di Benedetto M, Lindner H, Hare DL, Kent S. Depression following acute coronary syndromes: a comparison between the cardiac depression scale and the Beck depression inventory II. Journal of Psychosomatic Research. 2006; 60(1):13-20.

25. Perez GH, Nicolau JC, Romano BW, Laranjeira R. Depression and acute coronary syndromes: gender-related differences. Arquivos Brasileiros de Cardiologia. 2005; 85(5):319-26.

26. Parashar S, Rumsfeld JS, Spertus JA, Reid KJ, Wenger NK, Krumholz HM, Amin A, Weintraub WS, Lichtman J, Dawood N, Vaccarino V. Time course of depression and outcome of myocardial infarction. Archives of Internal Medicine. 2006; 166(18):2035-43.

27. Dias CC, Mateus PS, Mateus C, Bettencourt N, Santos L, Adao L, Sampaio F, Fonseca C, Simões L, Coelho R, Ribeiro VG. Acute coronary syndrome and depression. Revista portuguesa de cardiologia: orgao oficial da Sociedade Portuguesa de Cardiologia=Portuguese journal of cardiology: an official Journal of the Portuguese Society of Cardiology. 2005; 24(4):507-16.

28. Gholizadeh L. Cross-cultural validation of the Cardiac Depression Scale in Iran. Br J Clin Psychol. 2010; 49(4):51728.

29. Eng HS, Yean LC, Das S, Letchmi S, Yee KS, Bakar RA, Hung J, Choy CY. Anxiety and depression in patients with coronary heart disease: a study in a tertiary hospital. Iranian Journal of Medical Sciences. 2011; 36(3):201-6.

30. Moraska AR, Chamberlain AM, Shah ND, Vickers KS, Rummans TA, Dunlay SM, Spertus JA, Weston SA, McNallan SM, Redfield MM, Roger VL. Depression, healthcare utilization, and death in heart failure a community study. Circulation: Heart Failure. 2013 May 1; 6(3):387-94.

31. Blumenthal JA, Lett HS, Babyak MA, White W, Smith PK, Mark DB, Jones R, Mathew JP, Newman MF, NORG Investigators. Depression as a risk factor for mortality after coronary artery bypass surgery. The Lancet. 2003; 362(9384):604-9.

32. Mann DL, Zipes DP, Libby P, Bonow RO. Braunwald's heart disease: a textbook of cardiovascular medicine. Philadelphia, US: Elsevier Health Sciences; 2014 Jul 30.

33. Druss BG, Bradford DW, Rosenheck RA, Radford MJ, Krumholz HM. Mental disorders and use of cardiovascular procedures after myocardial infarction. JAMA. 2000; 283(4):506-11.

34. Safaie N, Jodati AR, Raoofi M, Khalili M. Depression in Coronary Artery Disease. Journal of Cardiovascular and Thoracic Research. 2012; 4(3):77.

35. Shokrgozar S, Ahmadi R, Khairkhah J, Moorosi M. Severity of Depression in Hospitalized Patients with Cardiovascular Diseases by Cardiac Depression Scale (CDS). Journal of Guilan University of Medical Sciences. 2015; 24(2):9-15. 